\title{
An unusual case of submental epidermoid cyst in a ten years old child: A case report
}

\author{
Anjani Kumar Jha, NandaKishor Sahoo
}

\begin{abstract}
Introduction: Epidermoid cysts of the neck occur less commonly than dermoid cysts of the head and neck. They are located mostly in the submental region and present as a painless slow growing swelling. The purpose of this article is to present an unusual case of submental epidermoid cyst which showed mobility and increase in the size on deglutition which is a very unusual finding. Case Report: $A$ 10-year-old female child reported to our centre with a complaint of painless swelling in the anterior midline of the neck. The swelling was about $5 \times 4 \mathrm{~cm}$ in size. On clinical and radiological examination a provisional diagnosis of submental epidermoid cyst was made. Surgical enucleation was done under General anesthesia via an intraoral approach. Conclusion: Typically these types of cysts are not attached to the hyoid bone, but in our case it was attached both to the hyoid as well as the
\end{abstract}

Anjani Kumar Jha ${ }^{1}$, Nanda Kishor Sahoo ${ }^{2}$

Affiliations: ${ }^{1} \mathrm{Dr}$ Anjani Kumar Jha, MDS, Assistant Professor, Division of Oral \& Maxillofacial Surgery, Department of Dental Surgery, Armed Forces Medical College, Pune, India-411040; '2Dr Nanda Kishor Sahoo, MDS, FIBOMS, Professor \& Head Of The Department Dept of Dental Surgery, Armed Forces Medical College, Pune, India-411040.

Corresponding Author: Dr Anjani Kumar Jha, Consultant Oral \& Maxillofacial Surgeon, \#661, $8^{\text {th }}$ Main, $6^{\text {th }}$ Cross, RPC Layout, Vijayanagar, Bangalore, Karnataka, India560040; Ph: +917795836390; Email: anjansmile@rediffmail.com

Received: 16 April 2011

Accepted: 01 August 2011

Published: 01 October 2011 mandible and movement on deglutition was present which is a rare finding not reported till date. Considering the size and the location of the cyst extraoral approach was ideal for complete enucleation. But in our case we could achieve complete surgical enucleation via intraoral approach.

Keywords: Submental Epidermoid; Intraoral Approach; Hyoid bone; Mandible

$$
* * * * * * * * *
$$

Jha AK, Sahoo NK. An unusual case of submental epidermoid cyst in a ten years old child: A case report. International Journal of Case Reports and Images 2011;2(10):10-13.

$$
* * * * * * * * *
$$

doi:10.5348/ijcri-2011-10-59-CR-3

\section{INTRODUCTION}

Epidermoid and dermoid cysts are nonodontogenic inclusion cysts lined by ectoderm $[1,2]$. They occur anywhere in the body, predominantly in areas where embryonic elements fuse together [3]. Most cases have been reported in ovaries and the testicles (80\%), with $7 \%$ occurring in the head and neck area and $1.6 \%$ within the oral cavity $[3,4]$. They represent $0.01 \%$ of all oral cavity cysts $[4,5]$. Epidermoid cysts of the neck are much less common than dermoid cysts of the head and neck. Most often they are located in the submental region [2]. They present as a painless slow growing midline swelling. The diameter can vary from a few millimeters to even $10 \mathrm{cms}$. The clinical diagnosis should be confirmed with histopathological examination [1]. We present an unusual case of submental epidermoid cyst in a girl child. 


\section{CASE REPORT}

A 10-year-old female child reported to our centre with a complaint of painless swelling in the anterior midline of the neck. The swelling became more obvious and moved up and down on deglutition. It was first noticed 15 days back and increased rapidly in size. There were no other associated symptoms like dysphagia, dysphonia or speech difficulty.

On general physical examination the child was moderately built, moderately nourished. There were no signs of anemia, icterus, cyanosis, clubbing or lymphadenopathy. Vitals were within normal limits. The medical history was insignificant.

On examination an ovoid midline swelling measuring about $5 \times 4 \mathrm{~cm}$ was seen in the submental region. The skin over the swelling was normal in appearance; there was no sinus, discharge or ulceration seen. The swelling was seen to move on deglutition. On palpation the swelling was soft to firm in consistency, non-tender, smooth and fluctuant. Skin over the swelling was pinchable and there was no lymphadenopathy. Transillumination test was negative. On intraoral examination there was no obvious swelling; it could only be felt on bimanual palpation. There was no pseudocyst or bluish discoloration seen in the floor of the mouth and there was no evidence of any oral or dental foci of infection (Figure 1).

Ultrasonography was suggestive of deep plunging ranula. Contrast enhanced CT (CECT) scan was suggestive of a cystic lesion in the submental region with a well defined thick capsule attached to the hyoid bone and genial tubercles of the mandible. There were no septations seen. Cyst contents were predominantly

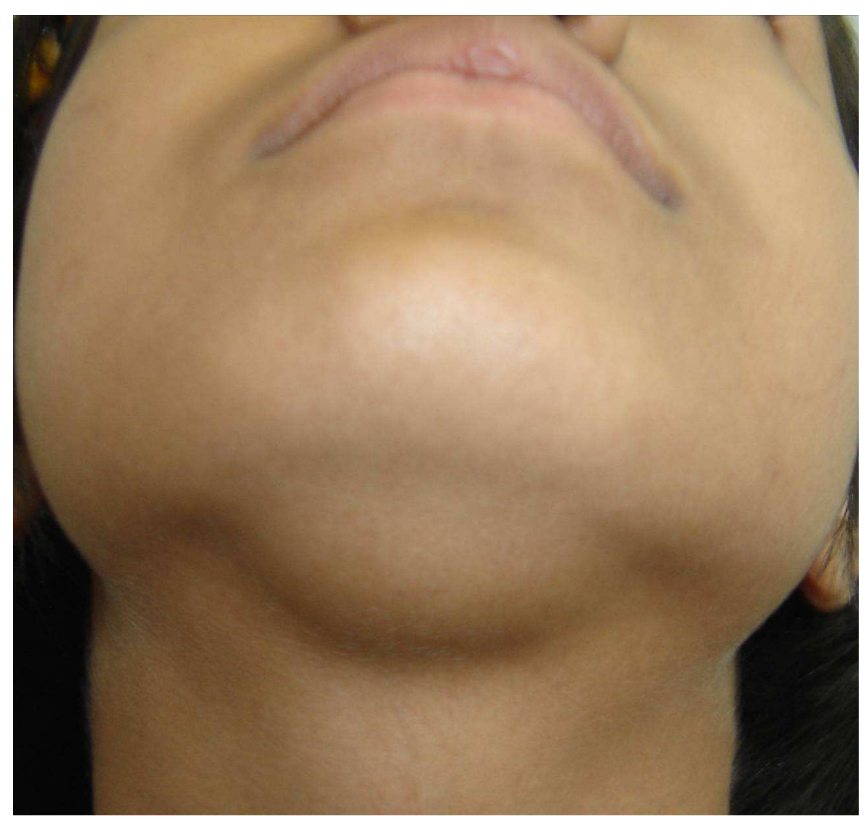

Figure 1: Preoperative view showing submental cystic swelling. radiolucent with interspersed multiple radio-opaque granules (Figure 2). Fine needle aspiration cytology was negative. A provisional diagnosis of dermoid or epidermoid cyst was made.

Surgical enucleation of the cyst was done via intraoral approach taking care not to injure the submandibular duct and other vital structures in the floor of the mouth (Figure 3). The cystic capsule was yellowish red in color and upon sectioning it was found to be filled with thick greyish white cheesy material. The enucleated cystic mass was sent for histopathological examination.

Histopathological examination confirmed the diagnosis of an epidermoid cyst with foreign body giant cell reaction. The cystic cavity was lined by 3 to 4 layers of stratified squamous epithelium with laminas of parakeratin on the surface. The supporting connective tissue was devoid of epithelial adnexa. Multinucleated giant cells were present (Figure 4).

The postoperative healing was uneventful. The patient was followed up on monthly basis. Presently after 15 months there is no recurrence (Figure 5).

\section{DISCUSSION}

Epidermoid cysts may be categorized as congenital or acquired based on their origin although there is no disparity between the two clinically or histologically [4, $5,6]$.

Ambiguity about their exact pathogenesis exists and dysontogenetic, traumatic, and thyroglossal anomaly theories have been postulated $[3,4,5]$.

Most dermoid cysts in the oral cavity floor are derived from epithelial debris or rests enclaved during midline closure of the bilateral first and second branchial arches. They may also result from

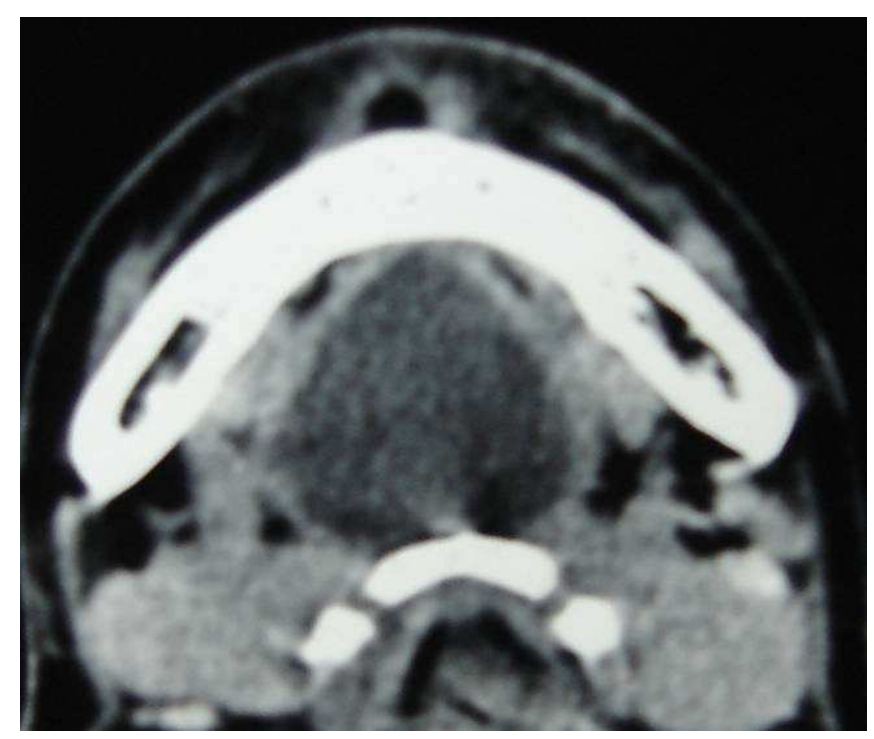

Figure 2: Axial section of the CT scan showing cystic lesion attached to hyoid bone and mandible. 


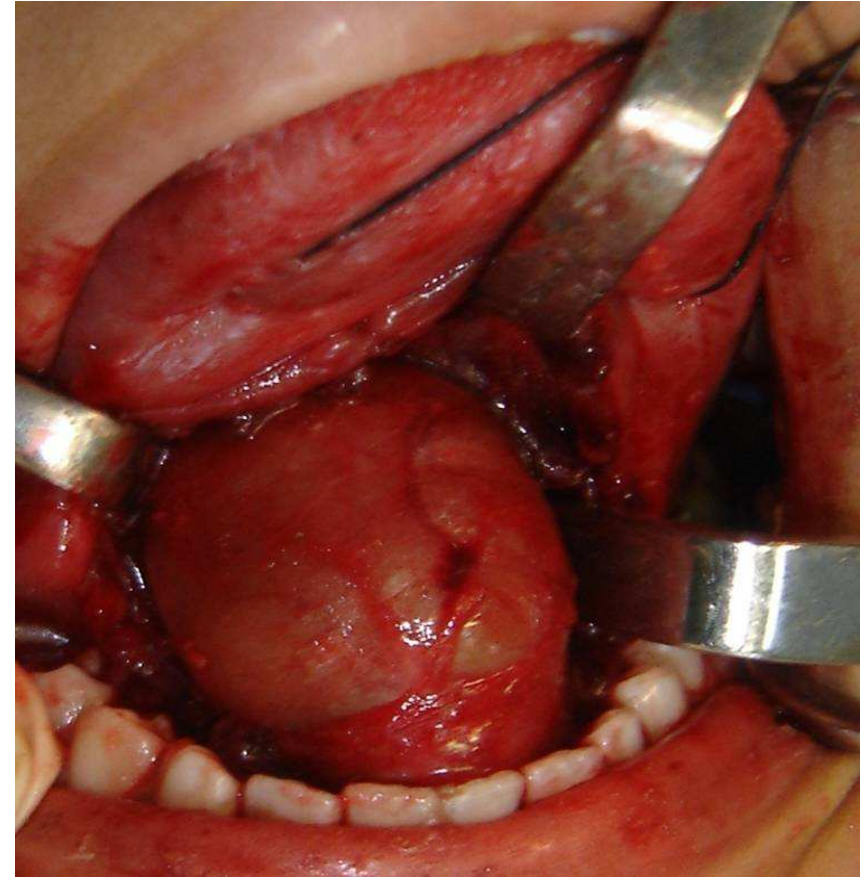

Figure 3: Intraoperative view showing cystic lesion exposed and being removed intraorally.

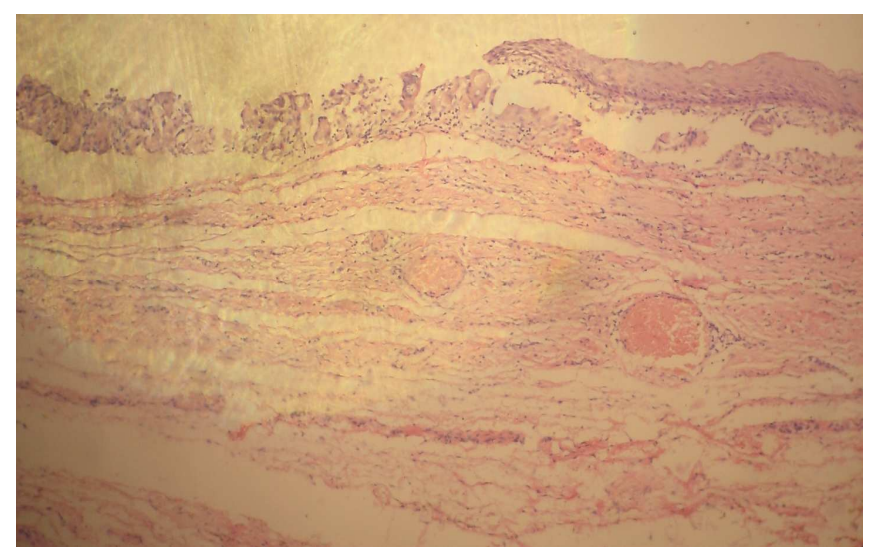

Figure 4: Histopathological slide shows features of an epidermoid cyst with foreign body giant cell reaction.

ectodermal differentiation of multipotential cells, most likely pinched off at the time of anterior neuropore closure [7]. The causes of both epidermoid and dermoid cysts include failure of surface ectoderm to separate from underlying structures, sequestration of surface ectoderm and implantation of surface ectoderm. Most congenital dermoid and epidermoid cysts probably arise due to an embryologic accident during the early stages of development between third and fifth weeks of gestation [8].

Traumatic or iatrogenic inclusion of epithelial cells or the blockage of a sebaceous gland duct has been postulated as the pathogenesis of acquired cysts $[5,6]$.

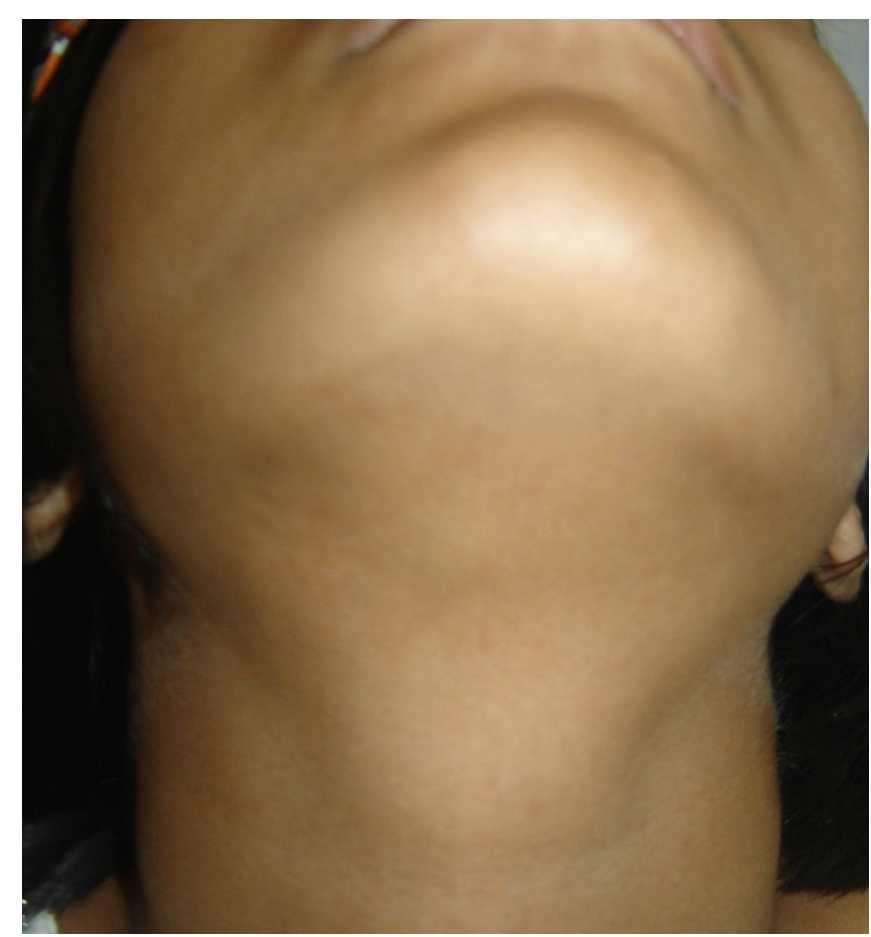

Figure 5: Post operative view showing no swelling in the submental region after 15 months of postoperative follow up.

However, some authors have also stated that the midline cyst may represent a diverse form of thyroglossal cyst $[5,6]$.

They may be found in any age group but show preponderance between 15-35 years of age with no gender predilection $[3,5]$. In our case the patient was 10 years of age.

Epidermoid cysts of the neck are much less common than the dermoid cysts and most often they are located in the submental region [9]. Typically, the mass is soft, mobile and unattached to the overlying skin. They have no intimate association with the hyoid bone and therefore do not move with tongue protrusion $[9,10]$. In our case the cystic capsule was closely attached to the hyoid bone as well as the mandible as was clearly seen in the CT scan. Hence, the swelling showed clear movement during the act of swallowing. This makes this case unique and rare.

The differential diagnosis comprise ranula, unilateral or bilateral blockade of Wharton's duct, lipoma, thyroglossal duct cyst, cystic hygroma, branchial cleft cysts, acute infection or cellulitis of the floor of the mouth, infections of the salivary glands, benign and malignant tumors, heterotropic gastrointestinal cyst and duplication foregut cyst [3, 4, 5].

Treatment consists of complete removal of the cyst. Recurrence is unlikely after complete removal. Approach for removal of the cyst depends on the location and size of the cyst. Most of the epidermoid/dermoid cysts are located superior to the 
mylohyoid muscle in the sublingual space and are removed by intraoral approach. Less commonly the lesion is inferior to the mylohyoid in the submental space presenting as an obvious neck swelling. These types of cysts are removed through an external submandibular approach [2, 3]. In our case although the cyst was of submental type and of considerable size, it was removed completely in toto by intraoral approach taking care of the complications and avoiding an obvious scar in a young female child.

Malignant transformation of oral cysts has not been reported. About $5 \%$ of dermoid cysts undergo malignant transformation into a squamous cell carcinoma [2].

\section{CONCLUSION}

It is not always true that submental epidermoid cysts are not attached to the hyoid bone or the mandible as seen in our case. They should be removed by intraoral approach as the first choice and resorted to extraoral approach only when the intraoral approach fails. The submandibular duct showed normal function with no decrease in salivary flow and there was no other comorbidity associated with the surgery.

\section{$* * * * * * * * *$}

\section{Author Contributions}

Anjani Kumar Jha - Substantial contributions to conception and design, Acquisition of data, Analysis and interpretation of data, Drafting the article, Revising it critically for important intellectual content, Final approval of the version to be published

NandaKishor Sahoo - Substantial contributions to conception and design, Acquisition of data, Analysis and interpretation of data, Drafting the article, Revising it critically for important intellectual content, Final approval of the version to be published

\section{Guarantor}

The corresponding author is the guarantor of submission.

\section{Conflict of Interest}

Authors declare no conflict of interest.

\section{Copyright}

(C) Anjani Kumar Jha et al. 2011; This article is distributed under the terms of Creative Commons attribution 3.0 License which permits unrestricted use, distribution and reproduction in any means provided the original authors and original publisher are properly credited. (Please see www.ijcasereportsandimages.com /copyright-policy.php for more information.)

\section{REFERENCES}

1. Laskaris G. Atlas colorido de doencas bucais na infancia e da adolescencia. $1^{\text {st }}$ ed. Porto Artes Medicas Sul/Livraria Santos Editora: 2000; p. 1-338.

2. Pancholi A, Raniga S, Vohra P A, Vaidya V. Midline submental epidermoid cyst: A Rare case. Internet $\mathrm{J}$ Otolaryngol. 2006;4(2).

3. Koca H, Seckin T, Sipahi A, Kaznae A. Epidermoid cyst in the floor of the mouth: Report of a case. Quintessence Int. 2007;38:473-7.

4. Ozan F, Polat H B, Ay S, Goza F. Epidermoid cyst of the buccal mucosa: A case report. J Contemp, Dent Pract. 2007;3:90-96.

5. Kandogan T, Koc M, Vadar E, Selek E, Sezgin C. Sublingual epidermoid cyst: A case report. J Med case reports. 2007;1:87.

6. Hemaraju N, Nanda S K, Mediker S B: Sublingual epidermoid cyst. Indian Journal of Otolaryngology and Head and Neck surgery. 2004;3:218-20.

7. Dimov ZH, Dimov K, Kirsten D, Baeva N, Yarmov N. Dermoid, epidermoid and teratoma cysts of the tongue and oral cavity floor. Khirugiia (Sofiia). 2000;56(2):30-2.

8. Smirniotopoulos J, Chiechi M. Teratoma, dermoids and epidermoids of the head and neck. Radiographs. 1995;15:1437-1455.

9. Koeller K K, Alamol, Adair C F and Smirniotopoulos J G. Congenital cystic masses of the neck: Radiologic Pathologic correlation. Radiographics. 1999;19:12146.

10. Park Y. Evaluation of neck masses in children. An Fam Phys. 1995;51:1904-12. 